\title{
Design and Analysis Comparison of Surface Acoustic Wave-Based Sensors for Fabrication Using Additive Manufacturing
}

\author{
Tayyab Waqar (D) and Sezgin Ersoy $(\mathbb{D}$ \\ Department of Mechatronics Engineering, Marmara University, Istanbul 34100, Turkey \\ Correspondence should be addressed to Tayyab Waqar; tayyabwaqar@gmail.com
}

Received 4 February 2021; Revised 23 May 2021; Accepted 29 May 2021; Published 14 June 2021

Academic Editor: Ibrahim Alarifi

Copyright (c) 2021 Tayyab Waqar and Sezgin Ersoy. This is an open access article distributed under the Creative Commons Attribution License, which permits unrestricted use, distribution, and reproduction in any medium, provided the original work is properly cited.

\begin{abstract}
Sensors have become an integral part of our everyday lives by helping us converting packets of data to make important decisions. Due to this reason, researches are done constantly to improve the fabrication processes of sensors by making them more userfriendly, less time-consuming, and more cost-effective. The application of any fabrication solution that offers those advantages will have a major impact on the manufacturing of modern sensors. To address this issue, a 3D printed Surface Acoustic Wave (SAW) temperature sensor is presented in this paper. The modelling and analysis of such a sensor have been performed for both aluminium and copper electrodes using COMSOL software. In total, 4 different sensing structures, 2 each for both aluminium and copper electrodes based one-port resonators, are designed and analysed for their application in temperature sensing. The resulting responses of those sensors are approximately $2.19 \mathrm{MHz}$ and $424.01 \mathrm{MHz}$ frequency ranges. The novelty lies in the possibility of mass-producing such a sensor using additive manufacturing will have a direct impact in the areas where conventional electronics cannot be utilized.
\end{abstract}

\section{Introduction}

Sensor-based technologies are playing an enormous role in fostering social and economic-based advancements in emerging economies all over the globe. To support the necessary technological development in the field of printed electronics [1-3], hence, in the field of sensors, both the researchers [4] and the industries [5] are working in alignment. Research and development are done to cut down the costs [6] and the time [7] to mass-produce sensors that are directly related to the efficiency [8-10] of the production and carry a huge benefit for the industry and also to the end-user. One such technique which can help the advancements towards this common goal is known as $3 \mathrm{D}$ printing, and it is already being employed to produce parts for industries such as automotive with greater speed and accuracy. To facilitate the process of $3 \mathrm{D}$ printing for sensor manufacturing, ink-jet printing, a technology commonly used in both personal and commercial environments, has surfaced in preference to conventional electronics fabrication practices [11-14]. Au et al. compared the cost of a traditionally manufactured sensor, i.e., via lithography, to a $3 \mathrm{D}$ printed technology, i.e., stereolithography and found the difference to be 15 USD [15]. Not only the cost but also the simplicity of the 3D printing technique plays an important role here as it makes the reproduction of the same structure with minimal human effort. In addition to that, the sensitivity and the accuracy of the printed sensor, compared to the traditional ways, are not affected $[16,17]$.

Several 3D printing technologies are being currently utilized and are also researched for their implementation in the sensor fabrication process, and one of them is based on Aerosol Jet (AJ) method which can directly print the required sensing structure on the provided substrate. AJ-based direct structure writing technique has been used for the realization of strain sensor [18-20], electrochemical and biosensors [21], antennas [22], electronic interconnect devices [23], transistors [24], solar cells $[25,26]$, electrothermal actuators [27], and 


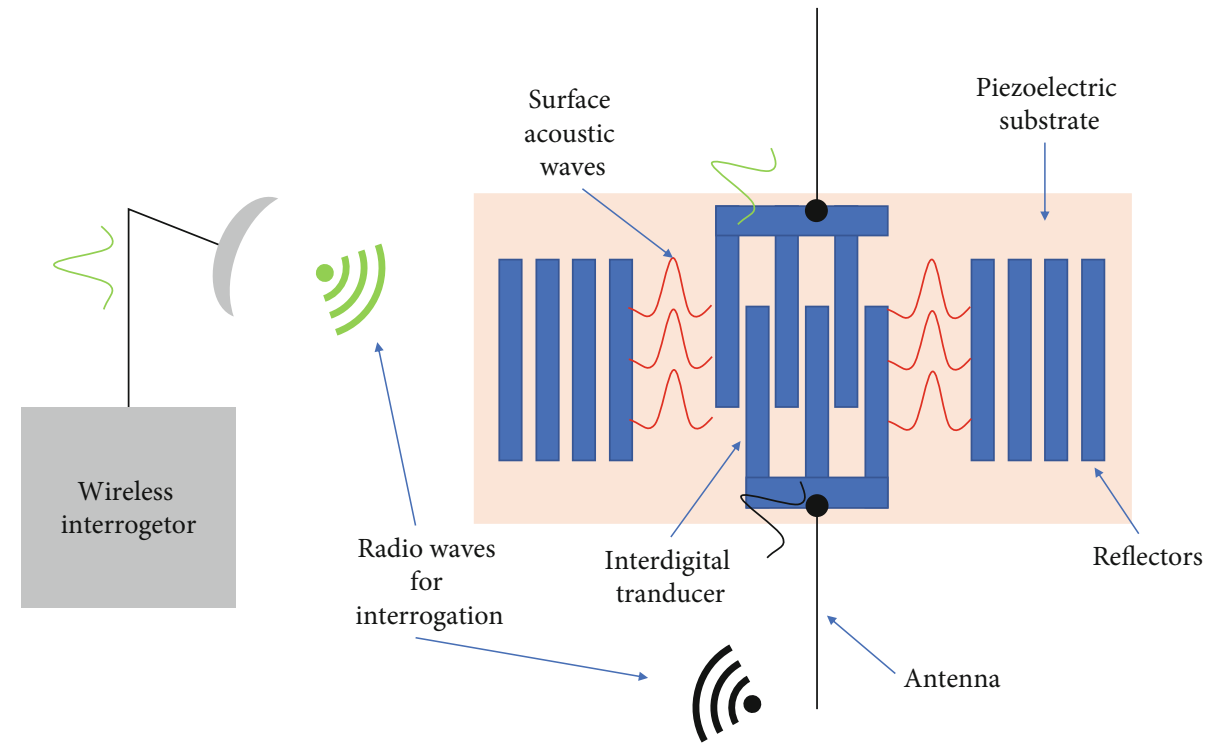

FIGURE 1: Operating principle of a one-port SAW-based resonator.
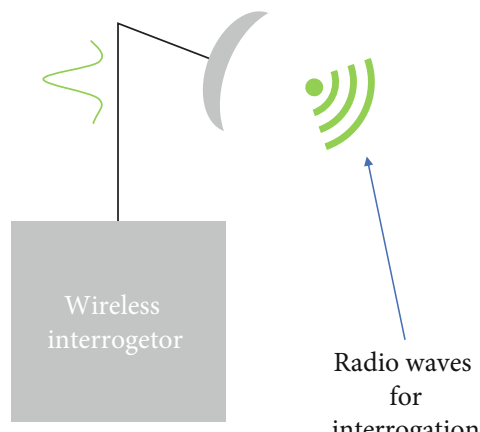

interrogation

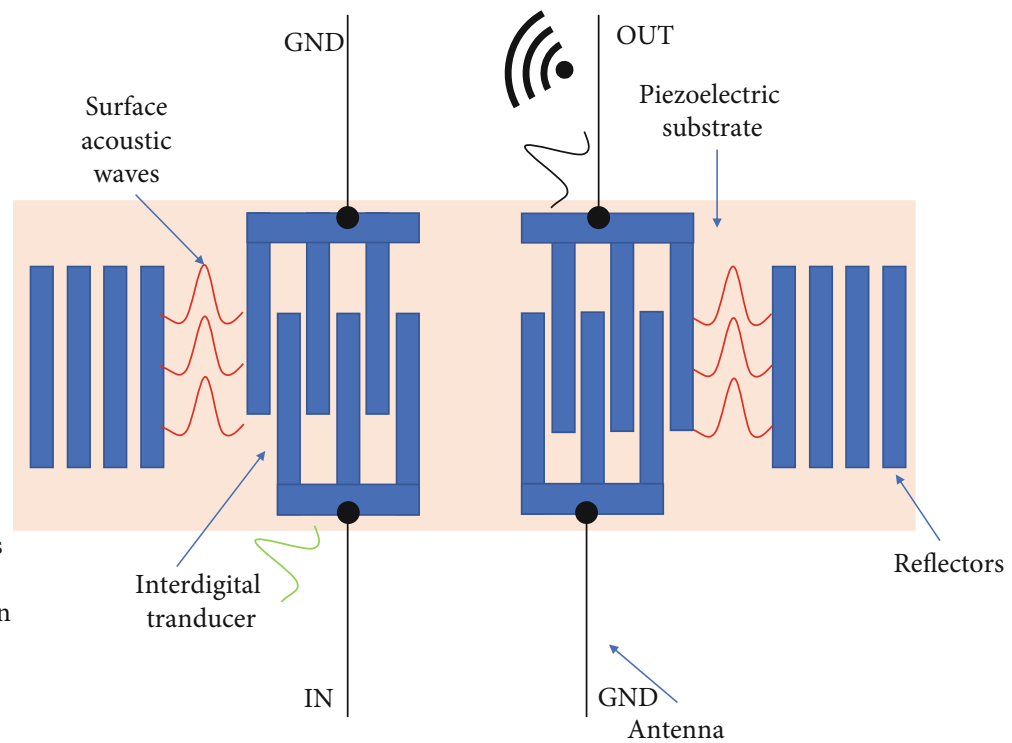

FIGURE 2: Operating principle of a two-port SAW-based resonator.

microbeams [28]. This works focuses on the use of the AJ-based printing method for the surface acoustic wave (SAW) based passive temperature sensor.

SAW-based devices use the principle of piezoelectric effect to convert an electrical signal to a mechanical wave, Rayleigh wave which is a transversal wave, which then propagates through the piezoelectric substrate to the other transducer which then changes it back to an electric signal. The properties of the Rayleigh wave and the principle of the piezoelectric effect need to be understood correctly for the application of them as a sensing device [29].

A radio wave is emitted using a wireless interrogation device which then energizes the SAW device using the opposite of the piezoelectric effect. The radio wave is transferred to interdigital transducers (IDT) via an antenna. The IDT converts the received electrical signal to a transversal wave, Rayleigh wave, which then propagates along the piezoelectric substrate to form a resonator. This structure has a unique resonating frequency at each temperature, and once the structural parameters of the SAW resonator are known, it can be utilized as a temperature sensing structure [30]. The schematic diagram illustrating the principle of operation of a typical single port SAW resonator is shown in Figure 1. One port resonator has IDT placed in the middle with reflectors on its left and right. Reflectors are used for sending back the generated surface acoustic wave.

Another type of SAW resonator is shown in Figure 2 which is known as the two-port SAW resonator. Due to its 
structure, it is mostly used for higher frequency oscillators and narrowband filters.

SAW-based sensors can provide medical [31], telecommunication [32], consumer electronics [33, 34], automotive [31], and industrial [33] sectors with a wide range of use cases. Due to their passive sensing capabilities, SAW devices can be utilized in harsh operating conditions where normal electronic circuits cannot be used, i.e., high temperatures. Normally, SAW-based sensors are fabricated using traditional methods which requires a clean room facility and the obligation to follow complicated several step processes [35] using lithography [36] but the advancements in the $3 \mathrm{D}$ printing technologies have allowed the researchers to apply them to sensor fabrication process. These technologies can directly print nanoparticles onto the substrate to fabricate a sensing structure. They decrease the process steps and allow the efficient use of the materials as compared to traditional lithography [37-40].

For this work, the AJ-based stereolithography printing method will be of the focus. This printing method will be explored for the fabrication of a SAW-based temperature sensor. The development of such a sensor is very much in line with the current requirements of many industries [41-45].

This paper presents 4 different designs of SAW-based sensors, to be employed for temperature sensing, based on YZ-cut lithium niobate with either aluminium or copper as the electrodes. The sensing structures are designed using both aluminium and copper electrode-based one-port resonator-based techniques. The models of the aforementioned sensors are mathematically designed, and analyses are performed using COMSOL software. Frequency and voltage-based responses of the sensing structures for all 4 proposed models are also calculated using COMSOL. The novelty lies in the possibility of mass-producing such a sensor using additive manufacturing will have a direct impact in the areas where conventional electronics cannot be utilized.

\section{Materials and Methods}

2.1. Material Selection. One of the most important steps in designing a SAW-based sensing device is the selection of the substrate and subsequently the electrode materials. Thermal coefficient, wave type, wave propagation velocity, and electromechanical coupling factor $\left(K^{2}\right)$ are some of the properties of the piezoelectric substrate which need to be considered for a SAW-based temperature sensor [46]. These properties are shown in Table 1 for some of the commonly used piezoelectric substrates.

For the design of a SAW-based temperature, the substrate with a higher thermal coefficient should be preferred due to the fact that it is directly related to the changes in the pitch of an IDT as a function of temperature. The change in length along the surface of the piezoelectric substrate will also affect the distance between the IDT electrodes, therefore, affecting the pitch of the device and since synchronous frequency and pitch are related, as in equation (1), therefore, the output signal will show a frequency shift. Depending on the mode of operation of the sensor, this frequency shift can be measured as either a shift in phase or a delay in time.
TABLE 1: Mechanical properties of some commonly available piezoelectric substrates.

\begin{tabular}{lcccc}
\hline Material & Orientation & $\begin{array}{c}\text { Thermal } \\
\text { coefficient } \\
\left.6 /{ }^{\circ} \mathrm{C}\right)\end{array}$ & $\begin{array}{c}\text { SAW } \\
\text { velocity } \\
(\mathrm{m} / \mathrm{s})\end{array}$ & $\begin{array}{c}\text { Coupling } \\
\text { coefficient } \\
(\%)\end{array}$ \\
\hline $\begin{array}{l}\text { Lithium } \\
\text { niobate }\end{array}$ & $\mathrm{Y}, \mathrm{Z}$ & 94 & 3488 & 4.6 \\
$\begin{array}{l}\text { Lithium } \\
\text { niobate }\end{array}$ & $128^{0}-\mathrm{Y}, \mathrm{X}$ & 75 & 3992 & 5.6 \\
$\begin{array}{l}\text { Lithium } \\
\text { tantalate }\end{array}$ & $\mathrm{Y}, \mathrm{Z}$ & 35 & 3230 & 0.66 \\
$\begin{array}{l}\text { Lithium } \\
\text { tantalate }\end{array}$ & $\mathrm{X}-112^{0}, \mathrm{Y}$ & 22.3 & 3295 & 0.75 \\
$\begin{array}{l}\text { Langasite } \\
\text { Quartz }\end{array}$ & $\mathrm{Y}, \mathrm{X}$ & 38 & 2330 & 0.37 \\
Quartz & $\mathrm{Y} \mathrm{ST,X}$ & -24 & 3159 & 0 \\
\hline
\end{tabular}

TABLE 2: Properties of commonly used conductor material for IDTs.

\begin{tabular}{lccc}
\hline $\begin{array}{l}\text { IDT electrode } \\
\text { conductor }\end{array}$ & $\begin{array}{c}\text { Substrate } \\
\text { adherence }\end{array}$ & $\begin{array}{c}\text { Electrical } \\
\text { resistivity }(\mu \Omega-\mathrm{cm})\end{array}$ & $\begin{array}{c}\text { Melting } \\
\text { point }\left({ }^{\circ} \mathrm{C}\right)\end{array}$ \\
\hline Gold & Poor & 2.2 & 2855 \\
Titanium & Good & 50 & 3286 \\
Tungsten & Normal & 5 & 5554 \\
Aluminium & Good & 2.65 & 2518 \\
Copper & Good & 1.7 & 2926 \\
\hline
\end{tabular}

To this end, looking at Table 1, lithium niobate should be preferred while quartz should be avoided for the application of SAW as a temperature sensor.

Another important thing to consider while designing a SAW sensing structure is the selection of the material for IDTs. Table 2 provides the properties of some of the most commonly used materials for IDTs [46]. YZ-cut lithium niobate will be used as a piezoelectric substrate with both aluminium and copper electrodes for IDT.

2.2. Sensor Design. Figure 3 describes the structural design parameters for the proposed SAW resonator-based temperature sensor. As depicted in Figure 3, the IDT structure is designed with a certain pitch among them, and the resulting surface acoustic wave is well-founded when the pitch of the IDT fingers and the wavelength of the surface wave are equal to each other. Equation (1) is employed to determine the resonant frequency $(f)$, which is a function used for measuring temperature, of the proposed structure, and its relation to the propagation velocity $\left(V_{s}\right)$ of the resulting surface wave.

$$
f=\frac{V_{s}}{\lambda_{0}}
$$

where $\lambda_{0}$ is the wavelength of the SAW. 


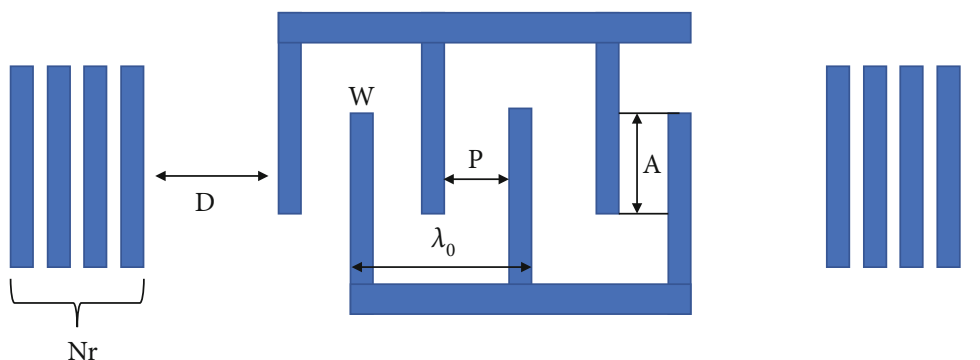

FiguRE 3: Design parameters for a single port SAW-based temperature sensor.

TABLE 3: Summary of geometric parameters for the proposed IDT and reflector structures for the SAW resonator.

\begin{tabular}{lccc}
\hline Parameter & Symbol & Values for device 1 & Values for device 2 \\
\hline Electrode finger width of IDT & $\mathrm{W}$ & $350 \mu \mathrm{m}$ & $2 \mu \mathrm{m}$ \\
Space between adjacent electrode fingers of IDT & $\mathrm{P}$ & $300 \mu \mathrm{m}$ & $2 \mu \mathrm{m}$ \\
Aperture width of the IDT finger & $\mathrm{A}$ & $6000 \mu \mathrm{m}$ & $300 \mu \mathrm{m}$ \\
Number of IDT finger pairs & No & 25 & 25 \\
Number of SAW reflector pairs & $\mathrm{Nr}$ & $200 \mu \mathrm{m}$ & 62 \\
Distance between IDT and reflectors & $\mathrm{D}$ & $200 \mu \mathrm{m}$ & $3 \mu \mathrm{m}$ \\
Thickness of IDT electrode fingers & $\mathrm{t}$ & & $0.5 \mu \mathrm{m}$ \\
\hline
\end{tabular}
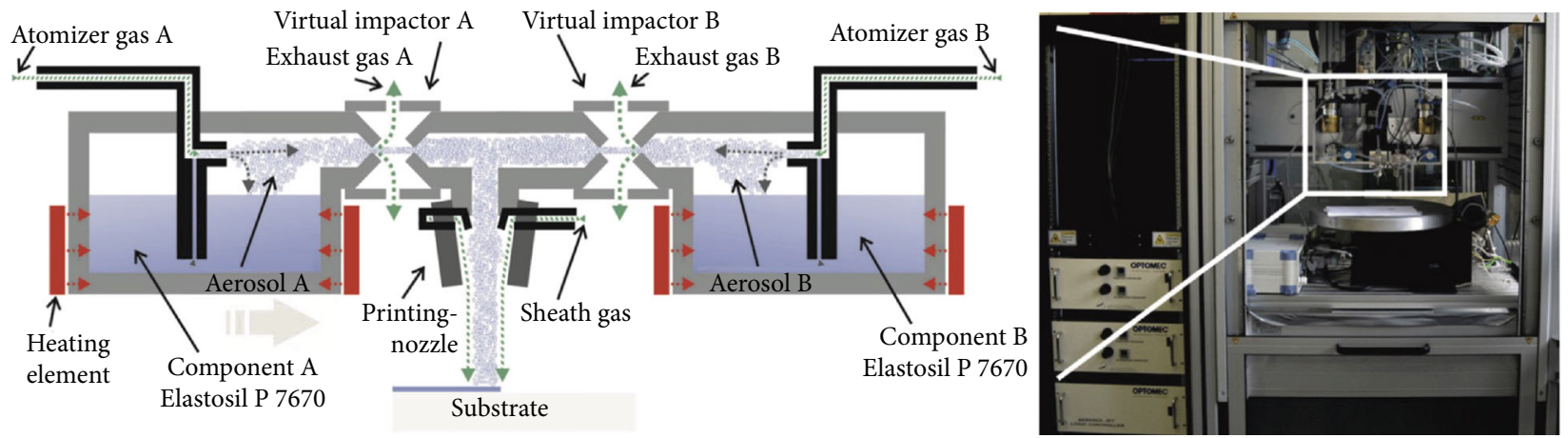

FIGURE 4: Functional block diagram for the generation of aerosol streams for a typical AJ-based printer [48].

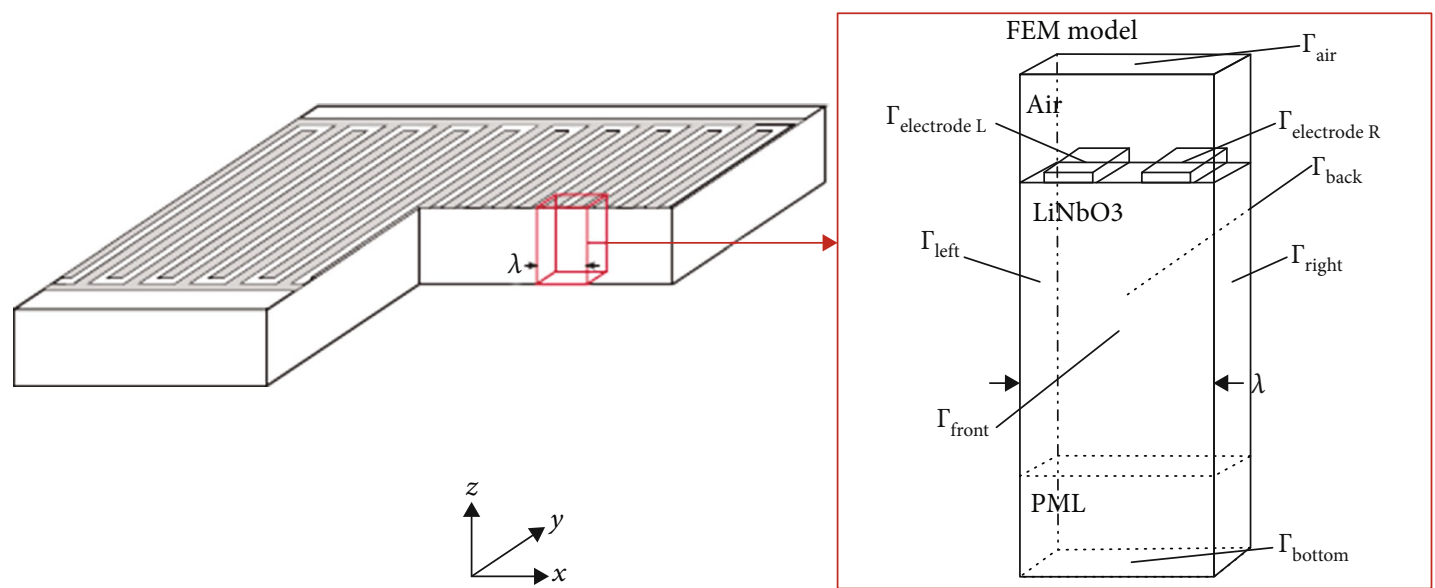

FIGURE 5: Finite element model for the analysis of the proposed SAW-based temperature sensing devices [49]. 


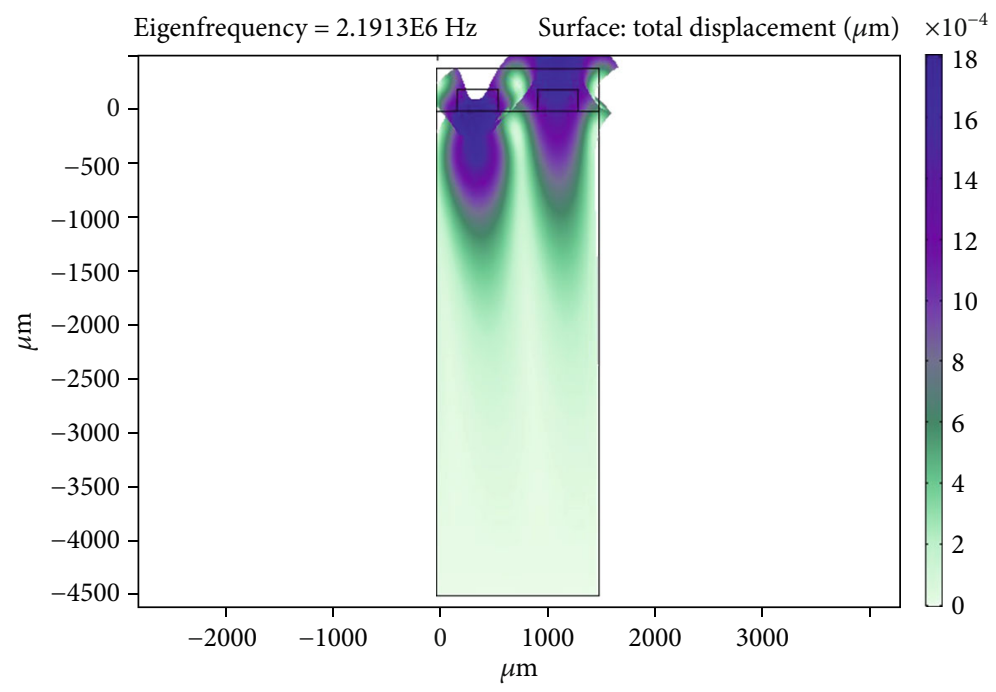

(a)

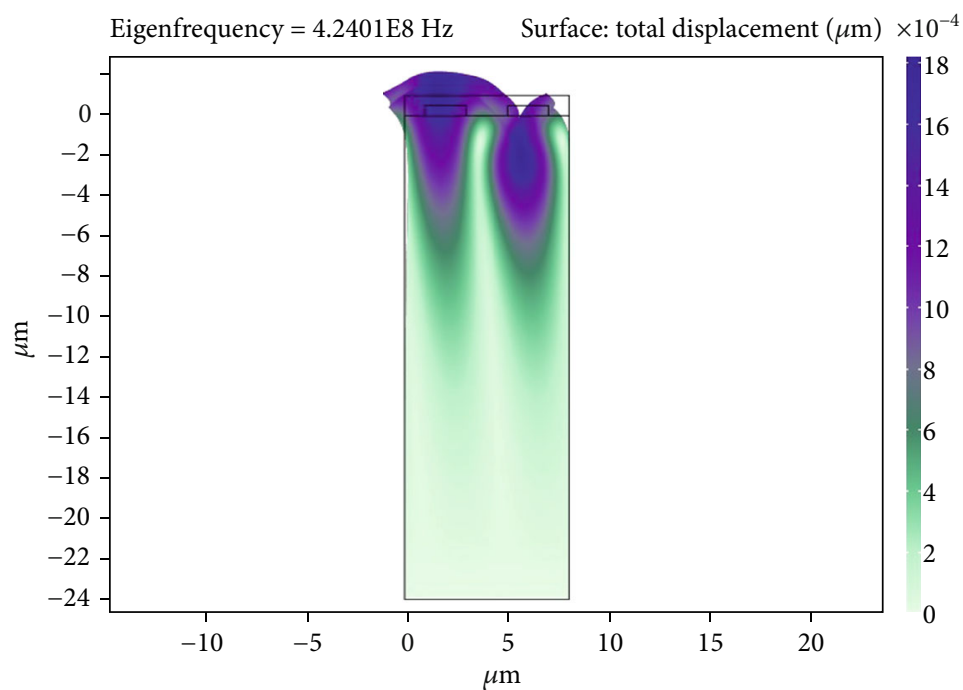

(b)

FIGURE 6: Resonant frequency mode plot of the proposed SAW temperature sensors with aluminium electrodes as IDTs: (a) device 1 and (b) device 2 .

The IDT structure needs to be quantified in order to develop its model. Figure 3 and Table 3 show the labelled IDT structure and its explanation, respectively.

In order to achieve the strongest IDT activation and phase superposition of SAW, the IDT pitch, which is $W+P$, should be equal to half of the SAW wavelength, as described by the wave interference principle. Therefore,

$$
W+P=N \frac{\lambda_{0}}{2}
$$

The distance between the IDT and the adjacent reflectors should also satisfy equation (3) to make sure that IDT receives the standing wave on its peak.

$$
D=\left(N-\frac{1}{2}\right) \frac{\lambda_{0}}{2} .
$$

Aperture width of the IDT fingers also plays an important role in the performance of the SAW resonator. Normally, it is between 50 and 100 times the SAW wavelength [47].

2.3. Aerosol Jet-Based 3D Printing. The possibility of the mass production of the $3 \mathrm{D}$ printed electronic structures is directly correlated to the advancements in the $3 \mathrm{D}$ printing technology, stereolithography. To this end, Optomec's AJ system, which using additive manufacturing, 


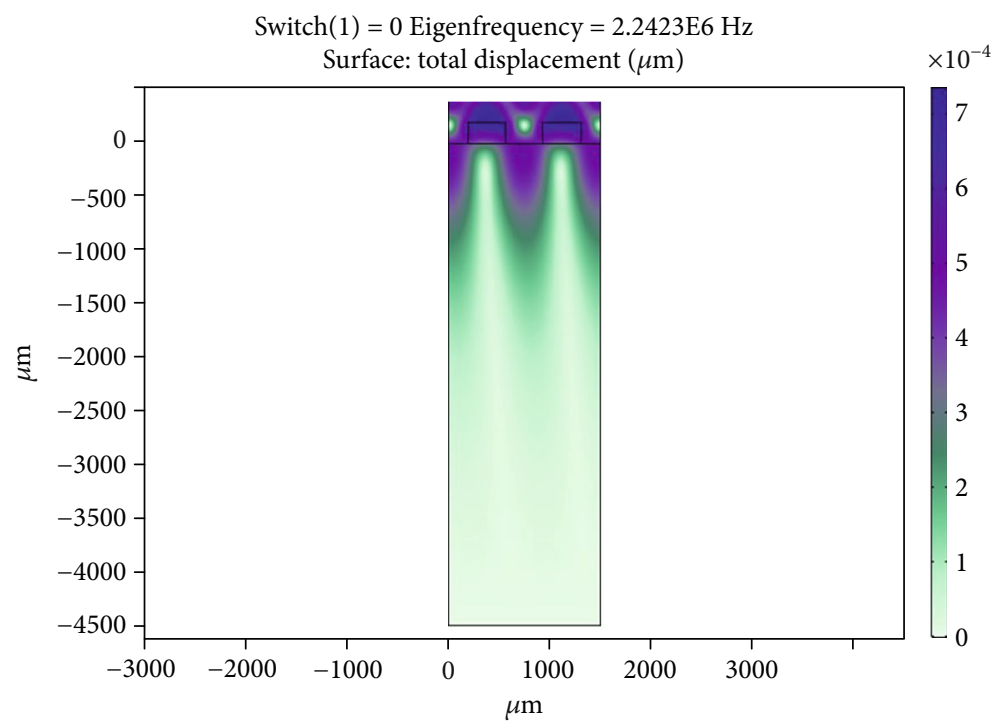

(a)

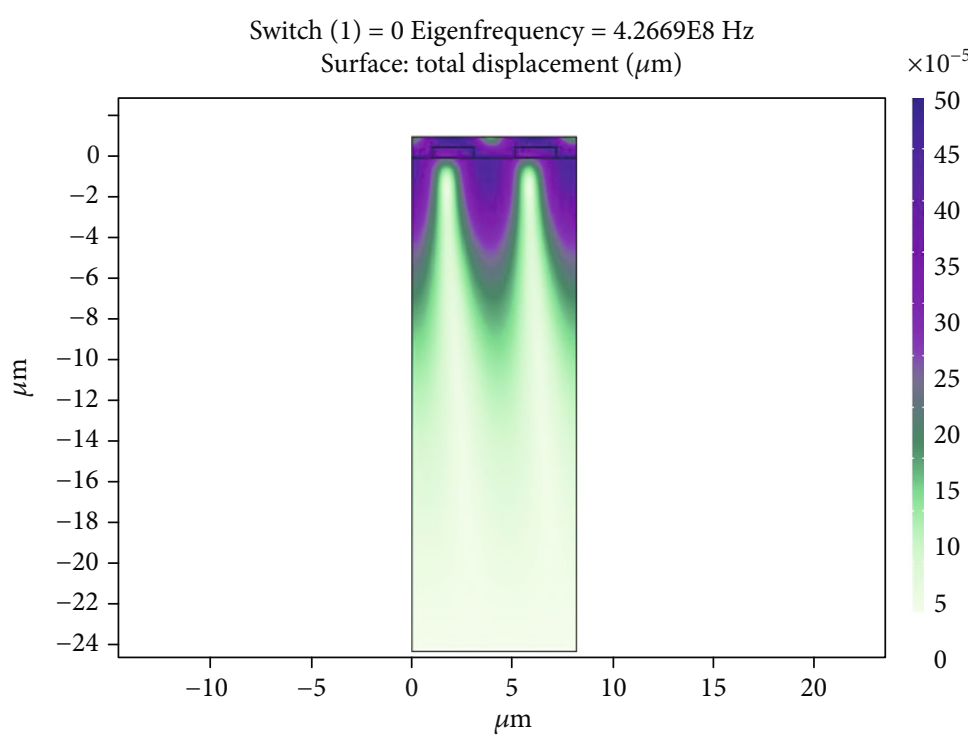

(b)

FIGURE 7: Antiresonant frequency mode plot of the proposed SAW temperature sensors with aluminium electrodes as IDTs: (a) device 1 and (b) device 2 .

offers the possibility of producing those minute electronic sensing structures to any desirable substrate using nanoparticles from the range of $1 \mathrm{~mm}$ to 10 microns. The working principle of the AJ-based system is shown in Figure 4 .

A pneumatic or more preferably ultrasonic, due to fewer suspension requirements, the based transducer is utilized to produce the aerosol flow which is then focused on the substrate to be deposited via a printing nozzle by forming a coaxial flow between the aerosol and inert gas streams acting as a sheath. The coaxial flow prevents the internal clogging in the printing nozzle. The width of the deposited structure on the substrate can be as minute as 10 microns if a 100 -micron printing nozzle is used. Once the deposition of the structure is finished, a sintered laser can be used to extract the final structure.

The fabrication of the proposed device using a direct $3 \mathrm{D}$ printing technique will be implemented for two different scenarios. The first scenario will have a YZ-cut lithium niobate as the piezoelectric substrate with a thin polyisobutylene film using aluminium for IDT electrodes. The second scenario will have copper IDT electrodes, and the rest will stay the same.

\section{Results and Discussion}

The finite element analysis of the proposed SAW-based temperature sensing devices is performed using COMSOL 

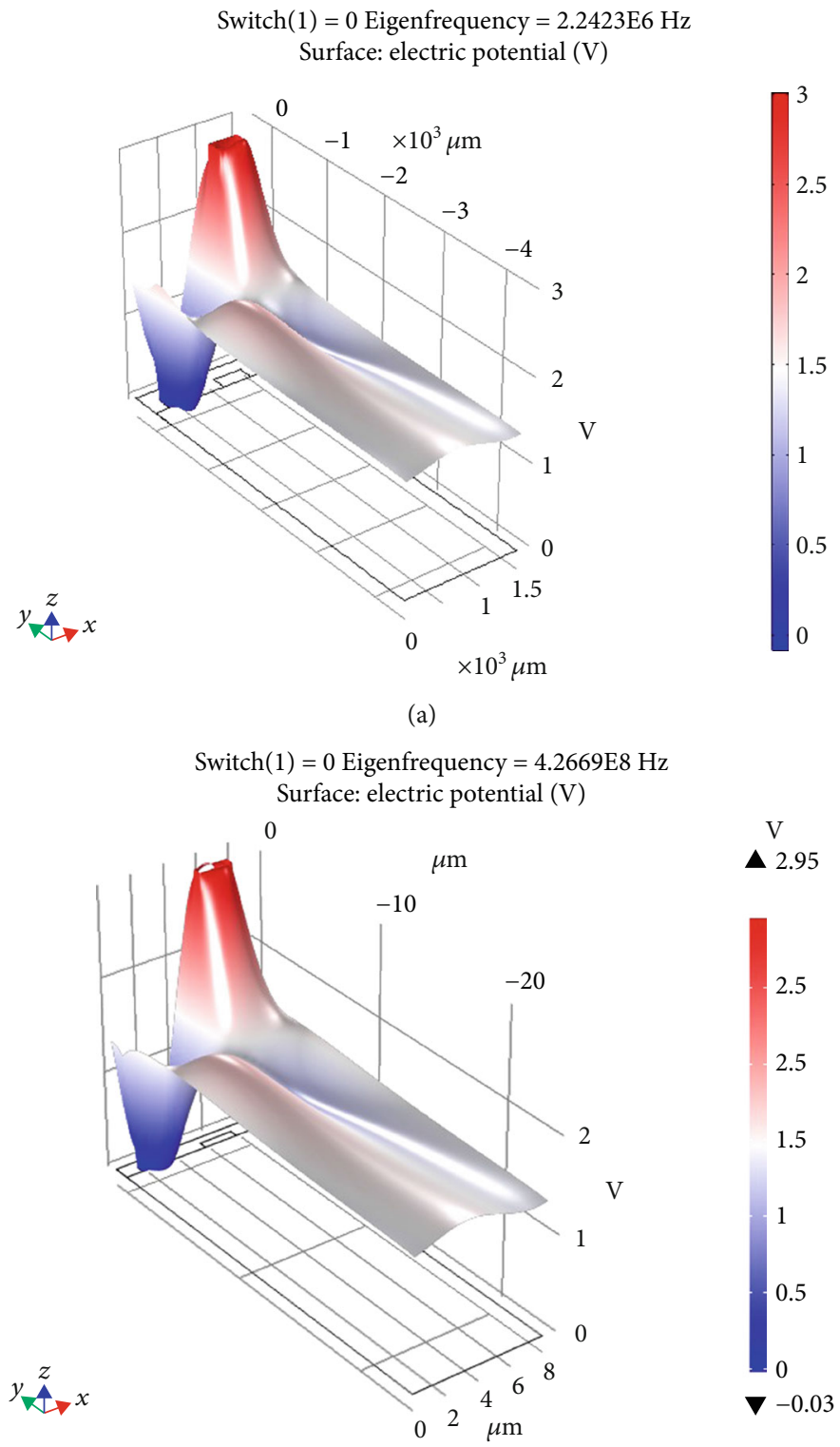

(b)

FiguRE 8: Electrical potential distributions at the 2nd eigenfrequencies of the proposed SAW temperature sensors: (a) device 1 and (b) device 2.

multiphysics. The results of those analyses are used to simulate and thus evaluate the performance of those devices. The configuration of the proposed devices is described in Section 2. The analysis can be performed using a pair of electrode fingers, since IDTs are periodic, for displacement. Again, using the boundary conditions, the aperture of the device can be assumed infinite reducing it to a few of the wavelength. The developed model is illustrated in Figure 5.

\subsection{Implementation of SAW Using Aluminium Electrodes.} The resonance frequency of the SAW-based resonator is calculated via piezoelectric material and eigenfrequency which in turn determines the velocity of the SAW in the designed structure. YZ-cut lithium niobate structure with the follow- ing constants is used for this study. Equations (4) defines the elasticity matrix as $E$ :

$$
E=\left[\begin{array}{cccccc}
242.4 & 75.2 & 75.2 & 0 & 0 & 0 \\
0 & 203 & 57.3 & 0 & 8.5 & 0 \\
0 & 0 & 203 & 0 & -8.5 & 0 \\
0 & 0 & 0 & 75.2 & 0 & 8.5 \\
0 & 0 & 0 & 0 & 59.5 & 0 \\
0 & 0 & 0 & 0 & 0 & 59.5
\end{array}\right] \times 10^{9}
$$




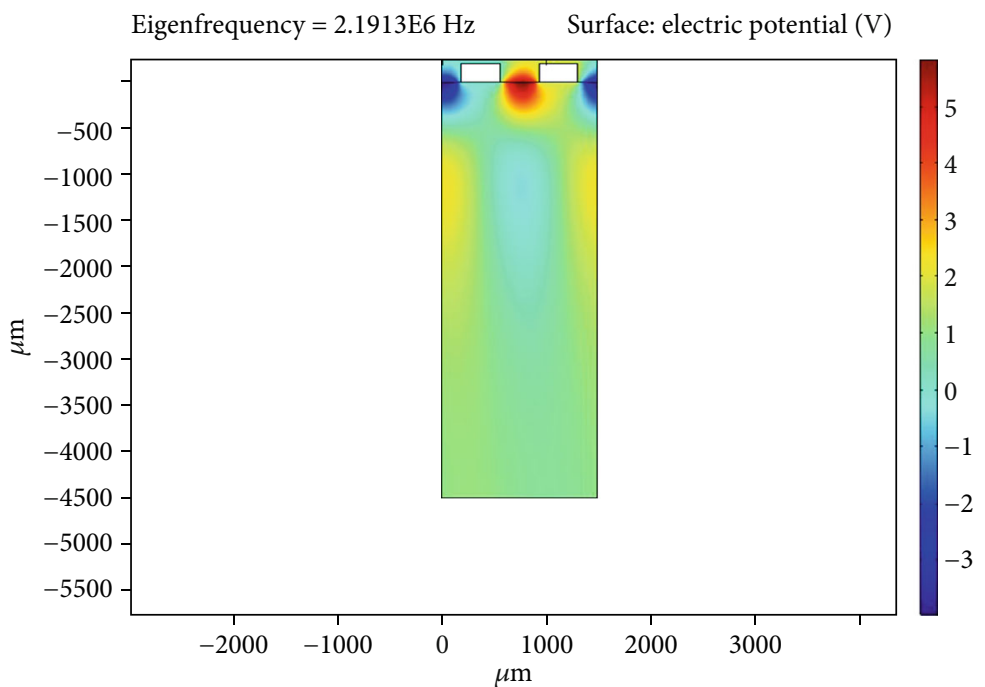

(a)

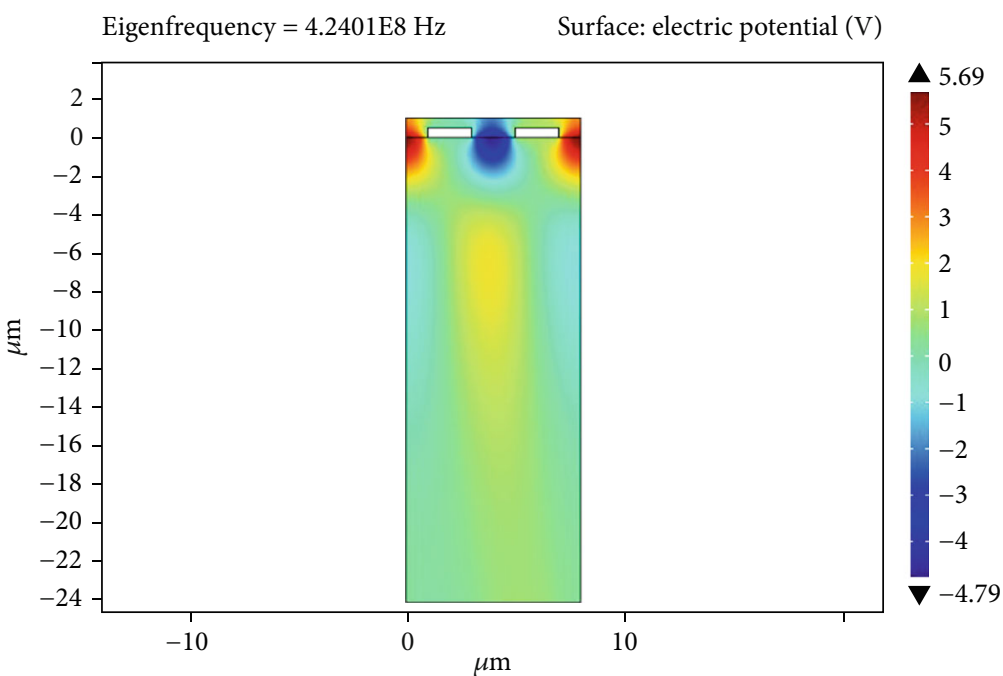

(b)

Figure 9: Sensors: (a) device 1 and (b) device 2.

The coupling matrix is shown in equation (5) as $C$ :

$$
C=\left[\begin{array}{cccccc}
1.33 & 0.23 & 0.23 & 0 & 0 & 0 \\
0 & 0 & 0 & -2.5 & 0 & 3.7 \\
0 & -2.5 & 2.5 & 0 & 3.7 & 0
\end{array}\right] \times C / m^{2}
$$

The relative permittivity, $\varepsilon$, is described in equation (6) as:

$$
\varepsilon=\left[\begin{array}{ccc}
28.7 & 0 & 0 \\
0 & 85.2 & 0 \\
0 & 0 & 85.2
\end{array}\right]
$$

The density is $0.918 \mathrm{~g} / \mathrm{cm}^{3}$ while Poisson's ratio is considered to be 0.48 and Young's modulus is $10 \mathrm{GPa}$. The usage of the periodic boundary condition implies that the electrical potential and the displacement are identical along both the vertical sections of the model.

The results of the analysis show the resonant frequencies, as shown in Figure 6, for SAW device 1 and device 2 to be at $2.19 \mathrm{MHz}$ and $424.01 \mathrm{MHz}$, respectively. The antiresonant frequencies, depicted in Figure 7, for SAW device 1 and device 2 are $2.24 \mathrm{MHz}$ and $426.69 \mathrm{MHz}$, respectively.

Considering the first and second eigenfrequencies of the SAW modes, shown in Figures 6 and 7, the electric potential distribution characteristics according to the illustrated solutions are shown in Figure 8 below.

The electrical response of both the proposed devices is presented in Figure 9. It can be seen from the graph that when an electrical potential is applied to the IDTs, the device 


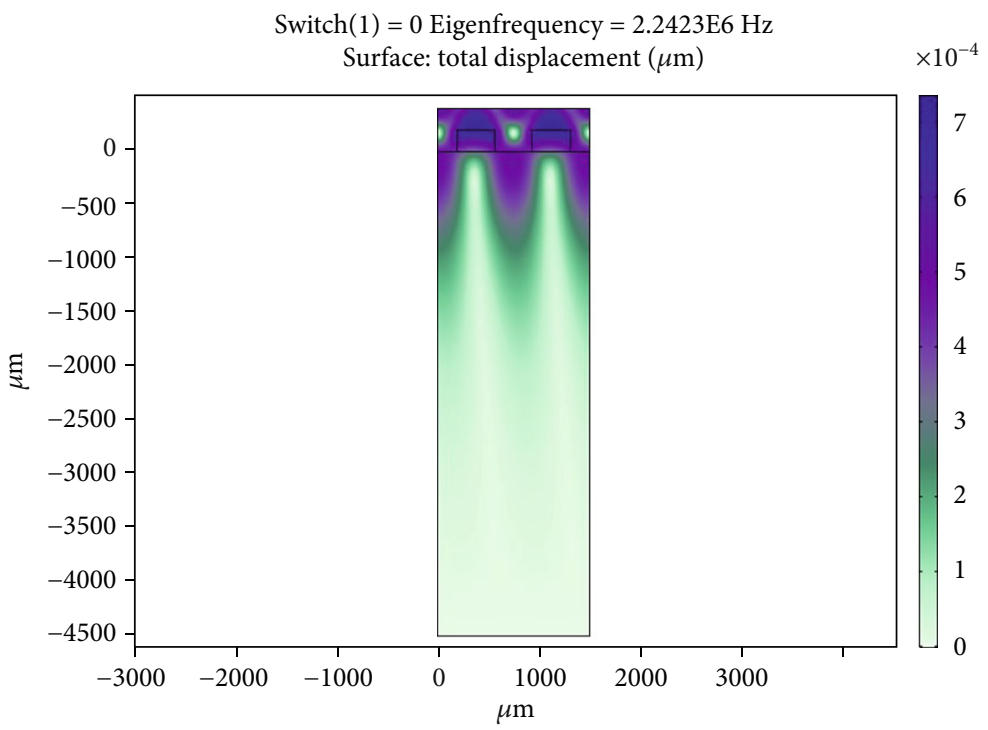

(a)

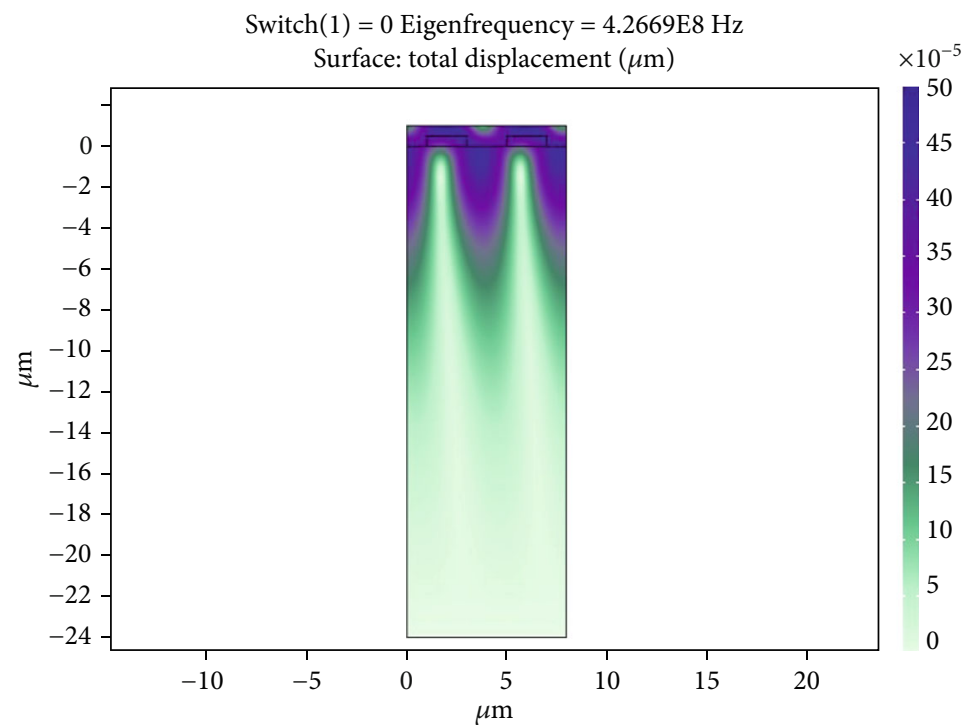

(b)

FIGURE 10: Resonant frequency mode plot of the proposed SAW temperature sensors with copper electrodes as IDTs: (a) device 1 and (b) device 2 .

experiences strain in its piezoelectric substrate and produces SAW that travels across the surface and thus causing deformation in the structure.

3.2. Implementation of SAW Using Copper Electrodes. The same analysis is performed for the device having copper electrodes. The results of the analysis show the resonant frequencies, shown in Figure 10, for SAW device 1 and device 2 to be at $2.07 \mathrm{MHz}$ and $398.22 \mathrm{MHz}$, respectively. The antiresonant frequencies, depicted in Figure 11, for SAW device 1 and device 2 are $2.43 \mathrm{MHz}$ and $401.57 \mathrm{MHz}$, respectively.

$2 \mathrm{MHz}$ and $4 \mathrm{MHz}$ SAW-based sensing structures are designed and modelled in this paper. In order to derive the output voltages and the displacement of the SAW sensors, transient analyses are performed using COMSOL software. The results for the field displacement are shown in Figures 6, 7, 10, and 11. Aluminium electrode-based oneport resonator shows a maximum displacement of $1800 \mu \mathrm{m}$ for device 1 and $12 \mu \mathrm{m}$ for device 2 . Meanwhile, these values for copper-based one-port resonator were near to $0 \mu \mathrm{m}$ for device 1 and $10 \mu \mathrm{m}$ for device 2 . Results show that electrodes based on aluminium are more efficient for the excitation of the sensing structure. Results also indicate that in all considered cases, the in-plane horizontal displacements are more important than the vertical ones, confirming thus the shearhorizontal nature of the generated waves. Results indicate that acoustic waves generated in the first device are in advance by about $0.05 \mathrm{~V}$, with respect to the second device. 


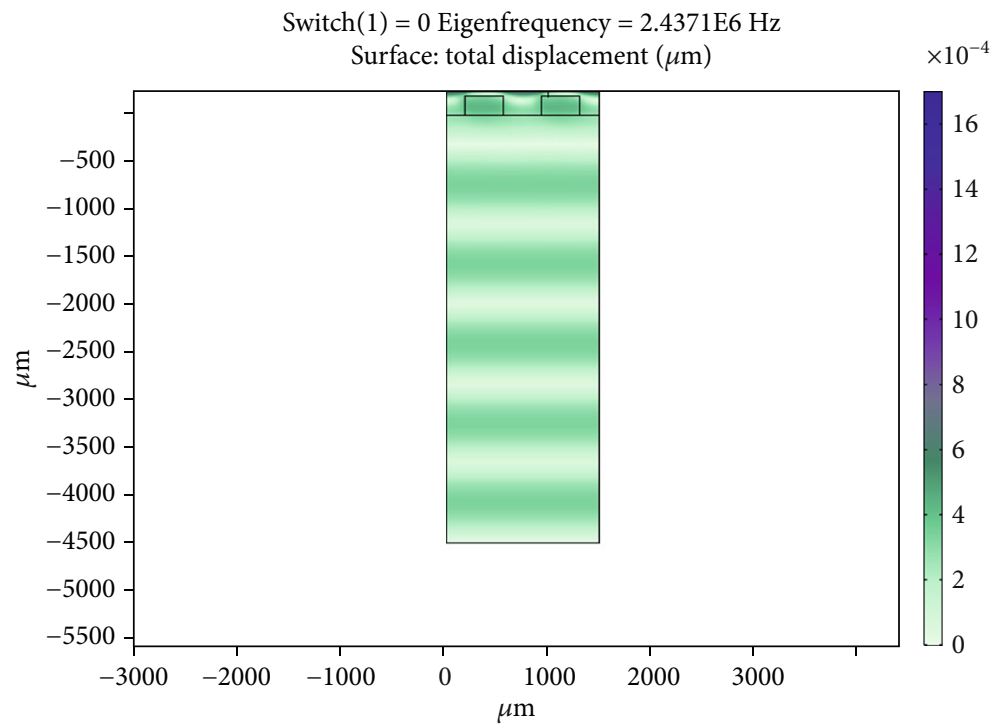

(a)

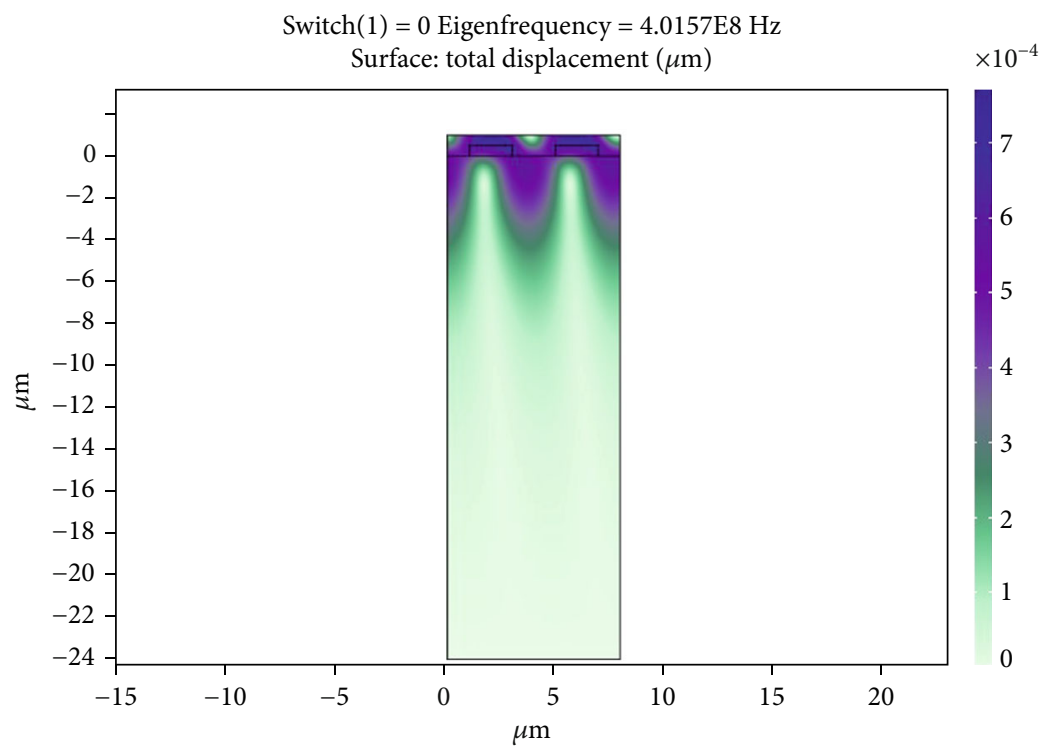

(b)

FIgURE 11: Antiresonant frequency mode plot of the proposed SAW temperature sensors with aluminium electrodes as IDTs.

\section{Conclusion}

SAW-based sensing technology in combination with the advancements in the $3 \mathrm{D}$ printing techniques shows promise for its implementation in wireless sensing applications. To this end, SAW-based temperature sensing devices were designed and modelled using COMSOL multiphysics and presented in this paper. All the structural designed parameters for both the proposed devices were calculated, and the simulations of their eigenfrequencies and impedances were performed using FEM. The designed sensors were found to be operating at $2.19 \mathrm{MHz}$ for device 1 and $424 \mathrm{MHz}$ for device 2 using YZ-cut lithium niobate as substrate and aluminium as the conducting metal for IDT electrodes. The proposed sensors have the capabilities of being a passive wireless sensing device. Finally, the findings presented in this paper pave the way for the possible fabrication of SAW-based temperature sensors with high accuracy using the AJ systembased direct 3D printing method.

\section{Data Availability}

All the data generated or analysed for this study are included in the article.

\section{Conflicts of Interest}

All the authors declare no conflict of interest. 


\section{References}

[1] Z. Zhan, J. An, Y. Wei, and D. Hejun, "Inkjet-printed optoelectronics," Nanoscale, vol. 9, no. 3, pp. 965-993, 2017.

[2] Y. Khan, A. Thielens, S. Muin, J. Ting, C. Baumbauer, and A. C. Arias, "A new frontier of printed electronics: flexible hybrid electronics," Advanced Materials, vol. 32, no. 15, p. 1905279, 2020.

[3] S. Khan, L. Lorenzelli, and R. S. Dahiya, "Technologies for printing sensors and electronics over large flexible substrates: a review," IEEE Sensors Journal, vol. 15, no. 6, pp. 31643185, 2014.

[4] M. G. Mohammed and R. Kramer, "All-printed flexible and stretchable electronics," Advanced Materials, vol. 29, no. 19, p. 1604965, 2017.

[5] A. K. Au, W. Huynh, L. F. Horowitz, and A. Folch, "3Dprinted microfluidics," Angewandte Chemie International Edition, vol. 55, no. 12, pp. 3862-3881, 2016.

[6] M. Berggren, D. Nilsson, and N. Robinson, "Organic materials for printed electronics," Nature materials, vol. 6, no. 1, pp. 3-5, 2007.

[7] J. Perelaer, P. J. Smith, D. Mager et al., "Printed electronics: the challenges involved in printing devices, interconnects, and contacts based on inorganic materials," Journal of Materials Chemistry, vol. 20, no. 39, pp. 8446-8453, 2010.

[8] R. F. Pease and S. Y. Chou, "Lithography and other patterning techniques for future electronics," Proceedings of the IEEE, vol. 96, no. 2, pp. 248-270, 2008.

[9] A. Nathan, A. Ahnood, M. T. Cole et al., "Flexible electronics: the next ubiquitous platform," Proceedings of the IEEE, vol. 100, no. Special Centennial Issue, pp. 1486-1517, 2012.

[10] R. R. Søndergaard, M. Hösel, and F. C. Krebs, "Roll-to-roll fabrication of large area functional organic materials," Journal of Polymer Science Part B: Polymer Physics, vol. 51, no. 1, pp. 16-34, 2013.

[11] M. Bozzi, C. Tomassoni, L. Perregrini, R. Bahr, and M. Tentzeris, "Additive manufacturing of substrate integrated waveguide components," Advanced Materials and Processes for RF and THz Applications (IMWS-AMP) 2016 IEEE MTT-S International Microwave Workshop Series on, pp. 1-4, 2016.

[12] D. L. Tong, A. A. Manga, P. Minard, A. Delattre, L. CrowtherAlwyn, and P. Borel, "Comparative study of WLAN dual-band monopole antennas printed and etched on paper and PET substrates," in 2016 46th European Microwave Conference (EuMC), pp. 1243-1246, London, UK, 2016.

[13] Y. Morimoto, M. Memarian, X. Li, and T. Itoh, "Open-end microstrip line terminations using lossy gray-scale inkjet printing," Microwave Theory and Techniques IEEE Transactions on, vol. 65, no. 12, pp. 4861-4870, 2017.

[14] A. Sahu, P. H. Aaen, A. Lewandowski et al., "Robust microwave characterization of inkjet-printed coplanar waveguides on flexible substrates," Instrumentation and Measurement IEEE Transactions on, vol. 66, no. 12, pp. 3271-3279, 2017.

[15] A. K. Au, W. Lee, and A. Folch, "Mail-order microfluidics: evaluation of stereolithography for the production of microfluidic devices," Lab on a Chip, vol. 14, no. 7, pp. 1294-1301, 2014.

[16] J. J. Adams, S. C. Slimmer, J. A. Lewis, and J. T. Bernhard, “3Dprinted spherical dipole antenna integrated on small RF node," Electronics Letters, vol. 51, no. 9, pp. 661-662, 2015.
[17] J. Kimionis, M. Isakov, B. S. Koh, A. Georgiadis, and M. M. Tentzeris, "3D-printed origami packaging with inkjet-printed antennas for RF harvesting sensors," IEEE Transactions on Microwave Theory and Techniques, vol. 63, no. 12, pp. 45214532, 2015.

[18] M. T. Rahman, A. Rahimi, S. Gupta, and R. Panat, "Microscale additive manufacturing and modeling of interdigitated capacitive touch sensors," Sensors and Actuators A: Physical, vol. 248, pp. 94-103, 2016.

[19] D. Zhang, C. Jiang, J. Tong, X. Zong, and W. Hu, "Flexible strain sensor based on layer-by-layer self-assembled graphene/polymer nanocomposite membrane and its sensing properties," Journal of Electronic Materials, vol. 47, no. 4, pp. 2263 2270, 2018.

[20] B. Andò, S. Baglio, S. La Malfa, and G. L'Episcopo, “All inkjet printed system for strain measurement," in SENSORS, 2011 IEEE, pp. 215-217, Limerick, Ireland, 2011.

[21] H. Yang, T. Rahman, D. Du, R. Panat, and Y. Lin, "3-D printed adjustable microelectrode arrays for electrochemical sensing and biosensing," Sensors and Actuators B: Chemical, vol. 230, pp. 600-606, 2016.

[22] T. Rahman, L. Renaud, D. Heo, M. Renn, and R. Panat, “Aerosol based direct-write micro-additive fabrication method for sub-mm 3D metal-dielectric structures," Journal of Micromechanics and Microengineering, vol. 25, no. 10, p. 107002, 2015.

[23] C. Goth, S. Putzo, and J. Franke, "Aerosol Jet printing on rapid prototyping materials for fine pitch electronic applications," in 2011 IEEE 61st electronic components and technology conference (ECTC), pp. 1211-1216, Lake Buena Vista, FL, USA, 2011.

[24] J. H. Cho, J. Lee, Y. U. Xia et al., "Printable ion-gel gate dielectrics for low-voltage polymer thin-film transistors on plastic," Nature materials, vol. 7, no. 11, pp. 900-906, 2008.

[25] A. Mette, P. L. Richter, M. Hörteis, and S. W. Glunz, "Metal aerosol jet printing for solar cell metallization," Progress in Photovoltaics: Research and Applications, vol. 15, no. 7, pp. 621-627, 2007.

[26] C. Yang, E. Zhou, S. Miyanishi, K. Hashimoto, and K. Tajima, "Preparation of active layers in polymer solar cells by aerosol jet printing," ACS Applied Materials \& Interfaces, vol. 3, no. 10, pp. 4053-4058, 2011.

[27] I. Ertugrul and T. Waqar, "Fabrication of bidirectional electrothermal microactuator by two-photon polymerization," Current Nanoscience, vol. 16, 2020.

[28] I. Ertugrul, "The fabrication of micro beam from photopolymer by digital light processing 3D printing technology," Micromachines, vol. 11, no. 5, p. 518, 2020.

[29] J. Kirschner, "Surface acoustic wave sensors (SAWS)," Micromechanical systems, 2010.

[30] B. Liu, C. Zhang, X. Ji, J. Chen, and T. Han, “An improved performance frequency estimation algorithm for passive wireless SAW resonant sensors," Sensors, vol. 14, no. 12, pp. 2226122273, 2014.

[31] https://www.fierceelectronics.com/components/acousticwave-technology-sensors.

[32] D. C. Malocha, "Evolution of the SAW transducer for communication systems," in IEEE Ultrasonics Symposium, 2004, vol. 1, pp. 302-310, Montreal, QC, Canada, 2004.

[33] S. Xu, C. Li, H. Li, M. Li, Q. Changqing, and B. Yang, "Carbon dioxide sensors based on a surface acoustic wave device with a 
graphene-nickel-L-alanine multilayer film," Journal of Materials Chemistry C, vol. 3, no. 16, pp. 3882-3890, 2015.

[34] D. C. Malocha, M. Gallagher, B. Fisher, J. Humphries, D. Gallagher, and N. Kozlovski, "A passive wireless multisensor SAW technology device and system perspectives," Sensors, vol. 13, no. 5, pp. 5897-5922, 2013.

[35] S.-H. Seo, W.-C. Shin, and J.-S. Park, "A novel method of fabricating $\mathrm{ZnO} /$ diamond/Si multilayers for surface acoustic wave (SAW) device applications," Thin Solid Films, vol. 416, no. 1-2, pp. 190-196, 2002.

[36] M. R. Zakaria, U. Hashim, and M. H. I. M. Amin, "Design and fabrication of IDT saw by using conventional lithography technique," Middle-East Journal of Scientific Research, vol. 18, no. 9, pp. 1281-1285, 2013.

[37] M. Maiwald, C. Werner, V. Zoellmer, and M. Busse, "INKtelligent printed strain gauges," Sensors and Actuators A: Physical, vol. 162, no. 2, pp. 198-201, 2010.

[38] B. Thompson and H.-S. Yoon, "Aerosol printed carbon nanotube strain sensor," in Smart Sensor Phenomena, Technology, Networks, and Systems Integration 2012, vol. 8346, article 83461C, International Society for Optics and Photonics, 2012.

[39] Y. Zhang, N. Anderson, S. Bland, S. Nutt, G. Jursich, and S. Joshi, "All-printed strain sensors: building blocks of the aircraft structural health monitoring system," Sensors and Actuators A: Physical, vol. 253, pp. 165-172, 2017.

[40] B. Thompson and H.-S. Yoon, "Aerosol-printed strain sensor using PEDOT: PSS," IEEE Sensors Journal, vol. 13, no. 11, pp. 4256-4263, 2013.

[41] W. C. Wilson and G. M. Atkinson, "Passive wireless sensor applications for NASA's extreme aeronautical environments," IEEE Sensors Journal, vol. 14, no. 11, pp. 3745-3753, 2014.

[42] R. R. Romanosky and S. M. Maley, "Harsh environment sensor development for advanced energy systems," in Micro-and Nanotechnology Sensors, Systems, and Applications V, vol. 8725 , article $87250 \mathrm{H}$, International Society for Optics and Photonics, 2013.

[43] E. J. Fichtel and A. D. McDaniel, High Temperature Strain Gage Technology for Gas Turbine Engines, 1994.

[44] J.-F. Lei and H. A. Will, "Thin-film thermocouples and straingauge technologies for engine applications," Sensors and Actuators A: Physical, vol. 65, no. 2-3, pp. 187-193, 1998.

[45] J. Watson and G. Castro, "A review of high-temperature electronics technology and applications," Journal of Materials Science: Materials in Electronics, vol. 26, no. 12, pp. 9226-9235, 2015.

[46] M. L. Chin, A fabrication study of surface acoustic wave devices for magnetic field detection, 2006.

[47] X. Ye, F. Lu, B. Liang et al., "Studies of a high-sensitive surface acoustic wave sensor for passive wireless blood pressure measurement," Sensors and Actuators A: Physical, vol. 169, no. 1, pp. 74-82, 2011.

[48] S. Reitelshöfer, M. Göttler, P. Schmidt, P. Treffer, M. Landgraf, and J. Franke, "Aerosol-Jet-Printing silicone layers and electrodes for stacked dielectric elastomer actuators in one processing device," in Electroactive Polymer Actuators and Devices (EAPAD) 2016, vol. 9798, article 97981Y, International Society for Optics and Photonics, 2016.

[49] H. Chambon, P. Nicolay, G. Bruckner, and A. Benjeddou, "Analysis of the sensitivity to pressure and temperature of a membrane based SAW sensor," International Journal of Smart and Nano Materials, vol. 8, no. 2-3, pp. 95-109, 2017. 